Utah State University

DigitalCommons@USU

\title{
Which Principal is the Right Principal? Student Achievement, School Finances, and Community Stakeholders
}

\author{
Sarah Nielsen \\ Utah State University \\ Amanda Taggart \\ Utah State University, amanda.taggart@usu.edu
}

Follow this and additional works at: https://digitalcommons.usu.edu/teal_stures

Part of the Teacher Education and Professional Development Commons

\section{Recommended Citation \\ Nielsen, S., \& Taggart, A. (in press). Which principal is the right principal? Student achievement, school finances, and community stakeholders. Journal of Cases in Educational Leadership.}

This Article is brought to you for free and open access by the Teacher Education and Leadership Student Works at DigitalCommons@USU. It has been accepted for inclusion in Teacher Education and Leadership Student Research by an authorized administrator of DigitalCommons@USU. For more information, please contact digitalcommons@usu.edu.

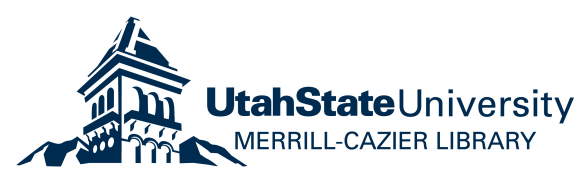


Which Principal is the Right Principal? Student Achievement, School Finances, and Community Stakeholders

Sarah Nielsen and Amanda Taggart

Utah State University 


\begin{abstract}
When a struggling high school may be placed on turnaround status during a bid for a school bond, the district considers replacing a beloved principal with a record of low test scores with an unpopular principal whose record shows increased student achievement. The school board must decide whether to prioritize finances, community support, student achievement, or state-level demands. This case presents many difficult decisions schools and districts are required to make. Key factors discussed in the case include principal turnover, student academic achievement, teacher retention, school culture, and power.
\end{abstract}

Keywords: principals, student achievement, politics of education 


\section{Which Principal is the Right Principal? Student Achievement, School Finances, and Community Stakeholders}

\section{Case Narrative}

\section{Context}

Located in the western United States, Stoneridge School District serves 10,000 students with one high school, two junior high schools, and 12 elementary schools. Half of the community feeding into the school district consists of retired couples and individuals. Approximately half of the district's schools, including the high school and the junior high school on which this case is focused, qualify for Title I funding. Since the implementation of NCLB and ESSA, student achievement has slowly, but steadily, declined across the district. At the same time, the number of students requiring English Language Learner (ELL) and Free and Reduced Lunch services has increased.

While the high school is relatively new, eight of the 12 elementary schools require extensive remodeling and refurbishment. In the year prior to the events described in this case, a multimillion dollar bond was proposed to renovate the schools. The local press reported that the public rejected the bond because it was too expensive and many individuals felt they would not receive any benefits from the tax. A new bond is set for the upcoming year and will ask for half of the previous bond's financing with the promise that the school district will raise the other half from private donors.

\section{Important Individuals}

The school district has experienced some administrative turnover in the past few years. Four years ago, Superintendent Cal was promoted. An experienced administrator from within the district, the schools over which he had authority experienced slow but steady academic growth 
while the rest of the district's academic growth declined. However, at the end of his second year as superintendent, he experienced serious medical issues that prompted his sudden retirement. Scrambling to find a new superintendent with just one month left in the academic year, the school board hired Superintendent Wilken, a district administrator without superintendent experience from a school district in another state.

When Superintendent Cal was hired as the superintendent, Mr. Jayne was promoted from junior high school principal to high school principal. Mr. Jayne had 20 years of prior administrative experience. When promoted, Superintendent Cal informed Mr. Jayne that the high school students had increased their proficiency scores by $1 \%$ on state-mandated end-of-year assessments for each of the past five years, but he was concerned that student participation in illegal (e.g., drug- and gang-related) activities taking place after school was resulting in legal consequences that were holding back their achievement. Superintendent Cal instructed Mr. Jayne to focus on promoting student participation in extracurricular activities as the means to continuing to improve student achievement, believing that increased participation in extracurricular activities would help decrease out-of-school trouble-making within the community. Prior to Mr. Jayne's appointment, approximately 150 of the 2,000 high school students participated in extracurricular activities. After two years of diligent work by Mr. Jayne and his two assistant principals, participation in extracurricular activities increased to over 300 students. Further, student attendance at sporting, performing arts, and other events tripled. However, standardized tests scores remained stagnant during that period. Although test scores did not improve, Mr. Jayne developed positive relationships with his staff, students, and parents who felt that he cared about student success in and out of the school setting. 
After Superintendent Wilken was hired, the newly appointed school board emphasized the importance of improving test scores, specifically mentioning their displeasure with the efforts of some principals, including Mr. Jayne. After the meeting with the school board, Superintendent Wilken talked to Mr. Jayne about his assessment scores. Superintendent Wilken emphasized that scores needed to increase but did not discuss with him Mr. Jayne's current efforts or plan.

Soon after assuming the superintendency and following the retirement of a principal, Superintendent Wilken hired Ms. Walker from outside the district to serve as the principal of one of the junior high schools, though she had no prior experience as a principal. As this school's achievement scores had dropped by $5 \%$ over the past eight years, Superintendent Wilken also instructed Ms. Walker to improve student achievement. In an effort to improve scores, Ms. Walker made many changes in her first year. One of the most controversial changes came via course offerings. Specifically, she eliminated honors courses, required all students to take two language arts courses instead of one, and allowed students to choose only one elective course each year instead of two. Elective courses were narrowed to band, choir, Spanish, and art. These changes were made so quickly and quietly, parents were unaware of them until the first day of school. When pressed for a reason for the changes, Ms. Walker cited low test scores and the need to reallocate more money for curricular support.

Furthermore, teachers were not made aware of Ms. Walker's course changes until their professional development meetings held one week before the school year began. At this time, they were also introduced to a new, purchased curriculum Ms. Walker required every teacher to use. Though neither the state nor the district endorsed any particular curriculum program, Ms. Walker's chosen curriculum was aligned to state standards and district curricular requirements and the provider boasted it was particularly successful when used with ELL students, who made 
up $20 \%$ of the school population. Ms. Walker felt the new curricular materials were perfect because they would help novice teachers begin the year on sure footing and help experienced teachers improve their instruction, as well. Teachers, however, complained that it was so prescriptive they were unable to tailor it to fit individual student needs. Throughout the year, Ms. Walker implemented a regular observation schedule with teachers including an in-the-moment feedback plan. This resulted in experienced teachers becoming increasingly weary of what they considered to be unwarranted badgering and interruptions during class and in front of students.

Soon after implementation of these changes, many students, parents, and teachers registered complaints with Ms. Walker about course offerings and the curriculum, though Ms. Walker made no adjustments based on their criticism. Complaints increased during the second semester as Ms. Walker implemented mandatory block tests where students took miniature endof-year standardized tests every three weeks in science, mathematics, and language arts courses. Complaints were registered with district-level leaders as well. However, at the end of the academic year, the junior high's proficiency level on state tests had increased by $6 \%$ while Mr. Jayne's high school proficiency dropped by $2 \%$ during the same period.

\section{The Case}

At the end of Ms. Walker's first year as principal at the junior high school and Mr. Jayne's third year as principal of the high school, the district faced a funding crisis. Three of its elementary schools would not be able to pass building codes without renovations over the summer. Because the original bond did not pass, the district lacked the money to repair the elementary schools while simultaneously maintaining current funding levels for the other district schools. As a result, the district made significant cuts to other budget items for the new school year, including to the number of teachers employed and to extracurricular funding. When the 
public expressed dissatisfaction with these decisions, the superintendent and members of the school board explained that these would be one-year funding cuts and that when the next bond passed, regular funding would be reinstated.

For the new school year, this meant that Mr. Jayne was unable to fund as many clubs and teams at the high school as he had in the past. The Activities Bus Program, a program that ensured students could take a bus home following after-school activities, was also terminated. This led to a drastic decrease in participation on the athletic teams and in the clubs that survived the budget cuts. Additionally, Mr. Jayne was unable to replace five teachers who were retiring or leaving and was also unable to renew teaching contracts for several first-year teachers whom he would have liked to retain. This led to a dramatic increase in class sizes at the high school, which placed a greater burden on his inexperienced teachers, two of whom left after the first quarter. Moreover, many of the experienced teachers were upset that their class sizes were larger than ever. While Mr. Jayne worked hard to provide leadership and assistance to newer teachers, he was more distant in his relationships with students and parents.

The district's budgetary cuts left Ms. Walker with comparable challenges to Mr. Jayne, especially regarding class sizes. However, she compensated for the budget decrease by increasing enrollments in elective classes. In addition, though the rate of teacher turnover in the district was approximately $7 \%$ over the past five years, nearly one quarter of the teachers at the junior high school left at the end of the previous year in protest of Ms. Walker's leadership, most of whom were veteran teachers. Therefore, Ms. Walker was able to hire new teachers rather than having to let any go.

At the same time the school district was dealing with the funding cuts and was readying its campaign to get the new bond passed, the state board of education began placing increased 
pressure on the district to increase student achievement. The district even received a formal warning from the state that several of its schools, including Sandstone High School, would be placed on turnaround status the next year if standardized test scores did not increase or if the school district could not produce a plan to improve student achievement. To address the state's concerns, the superintendent and the school board worked to create a plan to submit to the state should test scores continue to drop. As part of the plan, they determined that Ms. Walker's record of increased test scores would benefit the high school and that appointing her as its principal would, at the very least, delay the state's decision to place the high school on turnaround status.

A memo from the district office stating that Ms. Walker would become the new principal of the high school and would receive a significant pay raise was soon leaked to the public. In addition, the memo explained that Mr. Jayne would be made the principal of an elementary school but would not receive a decrease in pay as a signal to the public that he was not being demoted. The memo was leaked in mid-April, around the time campaigning for the new school bond was picking up steam. Prior to the leak, polls showed the bond would likely pass during the first week of June. However, students, parents, and teachers were furious when they learned of the proposed change in principals. Students held multiple rallies at the district office, often joined by their parents and some of their teachers. Students at the high school also walked out of school one day as a sign that they did not want Mr. Jayne to be replaced. Petitions were signed by thousands of members of the public. Though the proposed change in principals was not on the agenda for the next school board meeting, people poured into board meetings to speak against the change during the time allotted for public comments. By the second week in May, polls showed that the bond was likely to fail again. The superintendent and the members of the school 
board knew that if this second bond were to fail, the funding cuts from this year would have to be extended and even increased in order to pay for the necessary remodeling at the elementary schools. To make their decision even more difficult, the school district received a preliminary report card on each school's standardized test scores showing that the high school's test scores had not changed while the junior high school's scores increased by another four percent.

If lasting change comes by “persistence and time” (Bolman \& Deal, 2017, p. 137), should the district consider personnel changes at this time? In this case, Ms. Walker has been in her position a very short time. Should the school district consider other possible contributors to the increases in student achievement during her time as principal, rather than giving all the credit to her leadership? Alternatively, should Mr. Jayne be given more time in his position to increase achievement scores?

\section{Teaching Notes}

This case provides an example of the complexity that exists in making decisions in and for schools. One of the main challenges in the case focuses on the consequences of removing a popular principal from a low-performing school based on low achievement scores. While it may seem like a straightforward decision to replace the principal of a school with poor test scores with the principal of a school with rising test scores, this case asks educational leaders and decision makers to determine if the choice is really that simple, taking into account the input of and effects on students, teachers, the public, and government entities.

Threat rigidity theory encompasses the idea that organizations respond to external perceived threats by tightening structures, increasing centralized control, stressing conformity, emphasizing accountability measures, and discouraging innovative thinking (e.g., Olsen \& Sexton, 2009; Staw et al., 1981). In this case, district leaders are simultaneously reacting to the 
state threatening to move schools into turnaround status and to the threat of the public not supporting the bond issue. Such threats result in negative effects on the individuals and groups associated with the organization (i.e., administrators, teachers, students, parents, and community members), including anxiety and stress, decreased job satisfaction, increased conflict, the inability to creatively problem solve, and limited opportunities for professional learning (e.g., Daly et al., 2011; Staw et al., 1981).

Many of these negative effects can be found in this case, where the district leadership is focused on compliance with accountability mandates and sanctions rather than on capacitybuilding within their schools, even though prior research has shown that leadership approaches that are participative and inclusive and that build trust predict lower levels of threat-rigid responses among administrators and teachers in struggling schools (Daly, 2009). According to Daly (2009), "If schools and districts are to improve, then attention must be paid to not only sitelevel contexts but the broader impact of the district," including supporting "opportunities for flexible response and the sharing of leadership" (pp. 208-209). Doing so may negate some of the negative consequences of threat rigidity response and lead to innovation that both increases student achievement and teacher and administrator job satisfaction.

In this case, Principal Jayne faces an involuntary transfer due to the low test scores at his school coupled with no signs of academic improvement. Though several studies have shown that principal turnover negatively affects student achievement (e.g., Burkhauser et al., 2012; Mascall \& Leithwood, 2010), it appears as though the school board's initial decision to move Ms. Walker to the high school was based solely on the increased test scores at the junior high school during her first year as principal there. However, because the students, teachers, and parents in the case are against replacing Mr. Jayne with Ms. Walker, the superintendent and the school board must 
determine whether or not to follow through with their original decision by examining a complex array of factors that may affect their choice.

\section{Academic Achievement}

Apart from school leadership, research has shown that multiple factors influence student academic achievement, including student involvement in school activities and culture, opportunities for rigorous course-taking, and good teaching. Mr. Jayne was originally tasked by the superintendent with increasing participation in extracurricular activities among students at his school in order to lessen their involvement in troublesome activities. Although he has been successful in accomplishing this goal and research has shown that student participation in extracurricular activities has been positively associated with student achievement, including for racial/ ethnic minority students (e.g., Espinoza et al., 2013; Shifrer et al., 2015; Author, 2011), it could be that the first superintendent merely misdiagnosed the problem and that increasing student involvement in extracurricular activities was too simplistic an approach for improving student learning, as this ignores the idea that the classroom teacher has the most significant influence on student learning. According to Bolman and Deal (2017), "Faced with relentless pressure for immediate results, executives often conclude that...reorganizing is more likely to produce a quick hit" (p. 137). Such was the case with the superintendent's and the school board's plan. By replacing Mr. Jayne as the high school principal, the school district hopes to score a quick hit even though it is unclear if Mr. Jayne's efforts to support teachers and after school activities would produce better test scores in the long run if he were allowed to remain as principal. This consideration is supported by previous research which has shown that the longer principals remain in their positions, the greater the influence they have on academic achievement (Babo and Postma, 2017). Likewise, it is unclear whether or not Ms. Walker's tactics in her short 
time as principal led to the increased test scores at the junior high school or if other factors were at play.

In addition, research has shown that principals are more likely to leave schools with greater numbers of minority and low-income students (e.g., Podgursky et al., 2016). In this case, rather than wanting to leave them, Mr. Jayne has worked to better involve such students in the school culture. However, Ms. Walker has taken the opposite approach, greatly reducing the number of electives students are allowed to take, the topics of which often feed into the particular clubs and other extracurricular activities Mr. Jayne is trying to promote at the high school. Furthermore, Ms. Walker chose to decrease academic opportunities for poor and minority students at the junior high school as she eliminated honors courses from their curricular offerings, a move that contradicts the scholarship on this issue. For example, researchers investigating the influence of rigorous course-taking and student achievement have found positive impacts on student test scores and college enrollment through taking Advanced Placement (AP) and/or International Baccalaureate (IB) courses (e.g., Jackson, 2014) and taking more and higher-level mathematics courses (e.g., Mosqueda \& Maldonado, 2013; Author, 2011). Moreover, Ms. Walker eliminated teachers' ability to cater to individual student needs with her mandate to follow a prescriptive curriculum.

\section{Teacher Retention}

Principal turnover has also been related to lower teacher retention (Béteille et al., 2012; Ronfeldt et al., 2013) and negative changes in school culture, both of which have also been associated with student achievement (e.g., Dolton \& Newson, 2003). Consistently, principal support has been shown to influence teacher retention (e.g., Johnson et al., 2012; Simon \& Johnson, 2015), as teachers are more likely to stay in schools where they perceive greater levels 
of support from leaders (e.g., Hulpia et al., 2011; Johnson et al., 2012; Kraft et al., 2016; Ng \& Peter, 2010). For instance, in a qualitative study of 97 teachers working in a school with high numbers of disadvantaged students, teachers named creating a positive school culture as the top principal behavior that would influence them to stay in their schools (Greenlee \& Brown, 2009). Furthermore, frequent turnover in leadership has been found to be especially deleterious for high-poverty, low-achieving schools that often employ a large share of inexperienced teachers (Béteille et al., 2012). In this case, many experienced teachers left the junior high school in protest of Ms. Walker's tactics there, leaving already underserved students with more inexperienced teachers.

\section{Culture}

Prior research has also demonstrated that changes in the principalship often result in challenges to school culture, given that new leaders often introduce changes to existing school policies and practices (Burkhauser et al., 2012). Moreover, scholars have described how the frequency of principal turnover has affected the progression of trust between leaders and teachers (Macmillan, et al., 2004) and have determined that principal turnover negatively impacted subsequent principal leadership (Hanselman et al., 2016). In this case, Ms. Walker's history at the junior high school all but guarantees that she would implement immediate changes at the high school in regard to the curriculum, course offerings, testing procedures, etc. For instance, her top-down leadership style resulted in the principal solely deciding which curriculum each teacher would be required to use. Actions such as these are in direct opposition to the research that has demonstrated that teachers' commitment to their organizations is influenced by participative decision making (e.g., Hulpia et al., 2011). Furthermore, her relationships with teachers, parents, and students would also likely contribute to a large negative shift in the culture 
of the school. For example, her perceived poor treatment of teachers resulted in high teacher turnover at the junior high school after she arrived, which is consistent with research which has found that mistreatment by administrators is a factor in teachers deciding to leave their schools (Ng \& Peter, 2010).

Much like the literature on teacher retention, there is also scholarship connecting principal retention with feeling supported by the school district (e.g., Olberman, 1996). As such, if Mr. Jayne were to be removed from his current school, his feelings of non-support by the school district could affect his decision to stay in the district at all, causing the district to lose a popular school leader. Additionally, Olberman (1996) found that negative relationships with school councils, parents, and the broader community also influenced principals' decisions to leave, which may limit the time Ms. Walker could spend as the principal of the high school given her unpopularity among those groups.

It is clear that Mr. Jayne has garnered support from students, parents, and teachers, while Ms. Walker has cultivated poor relationships with those same constituents. District leaders must weigh these stakeholders' feelings with considerations of whether Mr. Jayne may just be an ineffective instructional leader and that a different leadership approach may be required to effect change at the high school level. However, given research which has shown that the rate of principal turnover influenced whether trust between principals and teachers progressed or stalled (e.g., Macmillan et al., 2004), if Ms. Walker were installed as the new principal at the high school over Mr. Jayne, it is likely that trust between the high school teachers and her would be blunted. In addition, removing Mr. Jayne would likely adversely impact the installation of Ms. Walker as the new high school principal, as principal turnover has been shown to negatively affect subsequent principal leadership (Hanselman et al., 2016). 


\section{Power}

Outside of students and teachers, the great financial needs of the school district in this case will require the school board to consider the power of public opinion when making its decisions. Because taxpayers will vote on a bond that would allow the school district to complete its school building projects, hire more teachers, and fund extraneous school activities and events, the superintendent and the school board must consider the voices of the taxpayers, especially at this vulnerable time when they are facing a public vote for school funds. However, the state also holds great power in requiring the school district to respond to a school turnaround warning. If the school board chooses to follow the public's desire to not move Mr. Jayne, the district may be more likely to get the funding it needs but will have difficulty explaining to the state what it is doing to improve test scores. Moving Ms. Walker to the high school would help the district provide an acceptable accountability plan to the state but would likely contribute to it losing the money it needs to renovate schools and restore funding levels. After the first failed bond vote, the district continued to focus their marketing for the new bond on making it less expensive rather than on helping community members, including those without school-age children, to understand that increasing funding for schools also increases the community's quality of life.

\section{Discussion Questions}

1. In this case, Mr. Jayne has been depicted as an inefficient administrator in regard to student achievement. Ms. Walker, however, has been described as a leader who can produce improvement in student achievement. To what degree should school district leaders take into account the fostering of a positive school culture when deciding whether to make changes in school leadership rather than relying solely on test scores? 
2. How might the cultures cultivated by Mr. Jayne and Ms. Walker at their respective schools contribute to student success?

3. In what ways might the school district's decisions influence the cultures of the schools affected, as well as the culture of the district as a whole?

4. What are the benefits and drawbacks of Mr. Jayne's leadership philosophy? Ms. Walker's?

5. Considering the student achievement outcomes at each school and the goals of public education, who would be a better fit to lead the high school, Mr. Jayne or Ms. Walker? Why?

a. What consequences, foreseeable and unforeseeable, might occur as a result of each choice by the school district?

b. Which aspects of threat rigidity should district leaders try to account for before making their decision on who should lead the high school?

6. How much should the school district take into account the public demand for participation in decision-making for schools? In what ways might the school district's decisions influence their relationship with the public?

7. How might the school district better market the proposed bond to help the public understand more sides of the issue?

8. Given that Mr. Jayne's original charge was to increase student participation in schoolsponsored activities, yet he is at risk of being removed from the school due to low achievement scores, what key communications must take place when a new principal or supervisor is hired? 


\section{Classroom Activities}

1. Divide the class in half and assign each side a position to argue: a) Mr. Jayne should be replaced as the high school principal, or b) Mr. Jayne should be kept in his position at the high school. During the debate, students should consider and name possible positive and negative consequences of each course of action.

a. During this debate or in small groups, students should discuss the potential benefits and drawbacks of maintaining Mr. Jayne in or removing him from the high school principalship from the perspective of each stakeholder group (i.e., students, teachers, school board, state office, etc.). Consider the following questions: Which stakeholders hold more power and influence? Which stakeholder group's needs or desires is most important? Whose needs or desires come first? Why?

2. Separate the class into groups. Assign each group to act as members of the school board and have them make a decision regarding the high school principal position. Then ask each group to craft an explanation for its decision to one of the following stakeholder groups: parents, teachers, the state office of education, Mr. Jayne, and Ms. Walker. Each group should provide an explanation for a different set of stakeholders.

3. Divide the class into four groups. Have each group examine the case and consequences through one of Bolman and Deal's (2017) four frames of organizational leadership. Each group should consider what the school board's best choice might be from that particular frame. Each group should present the case to the rest of the class from the lens of its chosen frame. 


\section{References}

Author (2011)

Béteille, T., Kalogrides, D., \& Loeb, L. (2012). Stepping stones: Principal career paths and student outcomes. Social Science Research, 41, 904-919.

doi:10.1016/j.ssresearch.2012.03.003

Bolman, L. G. \& Deal, T. E. (2017). Reframing organizations: Artistry, choice, and leadership (6th ed.). John Wiley \& Sons, Inc.

Burkhauser, S., Gates, S. M., Hamilton, L. S., \& Ikemoto, G. S. (2012). First-year principals in urban school districts: How actions and working conditions relate to outcomes. The RAND Corporation.

Daly, A. J. (2009). Rigid response in an age of accountability: The potential of leadership and trust. Educational Administration Quarterly, 45(2), 168-216. doi: $10.1177 / 0025 X 08330499$

Daly, A. J., Der-Martirosian, C., Ong-Dean, C., Park, V., \& Wishard-Guerra, A. (2011). Leading under sanction: Principals' perceptions of threat rigidity, efficacy, and leadership in underperforming schools. Leadership and Policy in Schools, 10, 171-206. doi:10.1080/15700763.2011.557517

Dolton, P., \& Newson, D. (2003). The relationship between teacher turnover and school performance. London Review of Education, 1(2), 131-140. doi: $10.1080 / 1474846032000098509$

Espinoza, J. A., Lunenburg, F. C., \& Slate, J. R. (2013). Hispanic middle school students and school sponsored activities: Relationships with achievement and behavior. Journal of Education Research, 7(4), 269-287. 
Greenlee, B., \& Brown, J. J. Jr. (2009). Retaining teachers in challenging schools. Education, 96109.

Hanselman, P., Grigg, J. K., Bruch, S, \& Gamoran, A. (2016). The consequences of principal and teacher turnover for school social resources. In G. Kao \& H. Park (Eds.), Family environments, school resources, and educational outcomes (pp. 49-89). Emerald Group.

Hulpia, H., Devos, G., \& Van Keer, H. (2011). The relation between school leadership from a distributed perspective and teachers' organizational commitment: Examining the sources of the leadership function. Educational Administration Quarterly, 47(5), 728-77. doi:10.1177/0013161X11402065

Jackson, C. K. (2014). Do college-preparatory programs improve long-term outcomes? Economic Inquiry, 52(1), 72-99. doi:10.1111/ecin.12040

Johnson, S. M., Kraft, M., \& Papay, J. P. (2012, October). How context matters in high-need schools: The effects of teachers' working conditions on their professional satisfaction and their students' achievement. Teachers College Record, 114, 1-39.

Kraft, M. A., Mariell, W. H., \& Yee, D. (2016, March). School organizational contexts, teacher turnover, and student achievement: Evidence from panel data. Working paper. The Research Alliance for New York City Schools, 1-41.

Macmillan, R. B., Meyer, J., \& Northfield, S. (2004). Trust and its role in principal succession: A preliminary examination of a continuum of trust. Leadership and Policy in Schools, 3(4), 275-294.

Mascall, B., \& Letihwood, K. (2010). Investing in leadership: The district's role in managing principal turnover. Leadership and Policy in Schools, 9(4), 367-383. doi:10.1080/15700763.2010.493633 
Mosqueda, E., \& Maldonado, S. I. (2013). The effects of English language proficiency and curricular pathways: Latina/os' mathematics achievement in secondary schools. Equity \& Excellence in Education, 46(2), 202-219. doi:10.1080/10665684.2013.780647

Ng, J. C., \& Peter, L. (2010). Should I stay or should I go? Examining the career choices of alternatively licensed teachers in urban schools. Urban Review, 42, 1123-142. doi: $10.1007 / \mathrm{s} 11256-009-0120-7$

Olsen, B., \& Sexton, D. (2009). Threat rigidity, school reform, and how teachers view their work inside current education policy contexts. American Educational Research Journal, 46(1), 9-44. doi:10.3102/002831208320573

Podgursky, M., Ehlert, M., Lindsay, J., \& Wan, Y. (2016). An examination of the movement of educators across and within three Midwest regions states. http://files.eric.ed.gov/fulltext/ED570453.pdf

Ronfeldt, M., Loeb, S., \& Wyckoff, H. (2013). How teacher turnover harms student achievement. American Educational Research Journal, 50(1), 4-36. doi:10.3102/0002831212463813

Shifrer, D., Pearson, J., Muller, C, \& Wilkinson, L. (2015). College-going benefits of high school sports participation: Race and gender differences over three decades. Youth \& Society, 47(3), 295-318. doi:10.1177/0044118X12461656

Simon, N., \& Johnson, S. M. (2015). Teacher turnover in high-poverty schools: What we know and what we can do. Teachers College Record, 117(3), 1-36.

Staw, B., Sandelands, L., \& Dutton, J. (1981). Threat rigidity effects in organizational behavior: A multilevel analysis. Administrative Science Quarterly, 26, 501-524. 